\title{
Human placental trophoblast culture: one-sided and two-sided models
}

\author{
BY DAVID L. BLOXAM \\ Reproductive Biology Laboratory, Royal Postgraduate Medical School Institute of Obstetrics and \\ Gynaecology, Queen Charlotte's and Chelsea Hospital, London W6 OXG
}

The investigation of human placental nutrient transfer and hormonal secretion presents a particular challenge because these processes depend on the intactness and orientation of the unicellular epithelial sheet of villous syncytiotrophoblast that mediates them. The isolated perfused placental cotyledon retains the architecture of the villi and has been very useful, but the presence of the non-trophoblastic placental cell types, and the complication of the effects of perfusion medium flows can be disadvantageous in certain types of study particularly at a cellular or molecular level. On the other hand, the development of methods for isolating syncytiotrophoblast microvillous and basal membrane vesicles has recently provided a great impetus to our understanding of the characteristics of the transport systems on these two membranes. Nevertheless, there is currently the need for intact pure trophoblast cell models for investigating mechanisms of transtrophoblast transfer and hormone secretion, and their relationships to intracellular metabolism.

The present paper outlines initial steps in the development and characterization of two such models.

\section{ISOLATION OF TROPHOBLAST CELLS}

As it is intrinsically difficult to isolate the pre-existing syncytiotrophoblast layer, the approach has been to separate cytotrophoblast cells which are thought to be precursors of syncytiotrophoblast in vivo (Carter, 1964; Boyd \& Hamilton, 1975). Evidence had been reported to suggest that when they are cultured, human placental cytotrophoblast cells spontaneously differentiate into multinucleated syncytiotrophoblast-like cells (Fox \& Kharkongor, 1970; Cotte et al. 1980; Lobo et al. 1985; Kliman et al. 1986). Thiede (1960) and others had originally obtained placental cells by trypsin treatment of villous tissue, but these, when cultured have generally given mixed cell populations (Contractor et al. 1984; Loke et al. 1986). Attempts have been made with varying success to purify cytotrophoblast from these cells by centrifugation (Stromberg et al. 1978; Zeitler et al. 1983; Kliman et al. 1986), sedimentation (Cotte et al. 1980; Nelson et al. 1986), or by employing culture conditions designed to select for trophoblast (e.g. Aladjem \& Lueck, 1981; Truman \& Ford, 1986; Contractor \& Sooranna, 1988; Loke \& Burland, 1988).

We have now found that by incubating term human placental villous tissue with bacterial protease and porcine pancreas acetone powder extract under appropriate conditions, it is possible to rupture the syncytiotrophoblast membranes, releasing cytotrophoblast cells, without releasing stromal or endothelial cells beneath the basement membrane. This method, which is described in detail elsewhere (Bax et al. 1989; Bullen et al. 1990), removes the need for a purification step. These cells were cultured in supplemented medium 199 , buffered at $\mathrm{pH} 7.4$ with either carbon dioxide-air (5:95, v/v), or 20 mmol HEPES/1 (Bax et al. 1989). 


\section{ONE-SIDED TROPHOBLAST MODEL}

Morphology. The morphology of the cultured cells was examined in detail by light and electron microscopy. The findings are summarized in Plates 1 and 2. Briefly, the isolated cells were obtained as clumps or single cells and ultrastructurally are simple, discrete and mononucleated. By $6 \mathrm{~h}$ they had started to flatten out and spread (Plate 1). At $48 \mathrm{~h}$ of culture they had merged into a continuous monolayer. Many of the cells had become multinucleated side by side with unaltered cells, and desmosomal junctions were seen between many of them (Plate 2). By $96 \mathrm{~h}$ most of the membranes between cells had disappeared giving rise to syncytial multinucleated sheets. There were extensive areas of featureless cytoplasm and the nuclei had formed clusters or strings (Plate 1). Electron microscopy showed the fine structure of the nuclei and cytoplasm to be very similar to those of syncytiotrophoblast in vivo (Plate 2; Bax et al. 1989).

Immunocytochemistry. The cells were also examined extensively by fiuorescence immunocytochemistry for the expression of various antigens characteristic of the different cell types present in placenta. The results which are reported elsewhere (Bax et al. 1989) confirmed that the cells obtained are trophoblast, with less than $5 \%$ contamination by other placental cell types.

Hormone secretion. Human chorionic gonadotrophin, which is thought to be produced by syncytiotrophoblast, has been shown to be secreted in increasing amounts in parallel with the formation of the multinucleated cells (Hoshina et al. 1982).

Conclusion. These and other results have allowed us to conclude that the initial cells are cytotrophoblast and that they differentiate during $4 \mathrm{~d}$ of culture into cells with morphological and immunocytochemical properties of villous syncytiotrophoblast (Bax et al. 1989).

Further work clearly needs to be done to establish to what extent the trophoblast cell layer in this model behaves as it does in vivo, but it does seem to be potentially useful for the investigation of trophoblast uptake and secretion via the microvillous membrane, and for the study of trophoblast metabolism and differentiation.

\section{TWO-SIDED MODEL}

To investigate transtrophoblast transfer this trophoblast layer on a permeable membrane needed to be cultured with medium on both sides. After trying a number of different support matrices, including reconstituted collagens and plastic membranes, we have been most successful with amniotic membrane.

The amnion cells and fibroblasts associated with the amniotic membrane were lysed and removed by treatment with $20 \mathrm{mmol}$ ammonium hydroxide/l. After extensive washing, pieces of the cell-free amniotic membrane were stretched across the bottom of polypropylene cylinders, the units suspended in plastic culture wells with medium on both sides and cytotrophoblast cells plated onto the upper surface. The method is given in detail elsewhere (Bullen et al. 1990).

Morphology and immunocytochemistry. The morphology and immunocytochemical properties of these cells were essentially identical with those of the conventional one-sided culture, except that differentiation was more rapid being complete in $2 \mathrm{~d}$ instead of $4 \mathrm{~d}$. Plate 3 shows the development of the layer as seen by light microscopy of stained cross-sections, and Plate 4 as seen from above by scanning electron microscopy. By plating the cells at a density of $6 \times 10^{5}$ cells per $\mathrm{cm}^{2}$ it was possible to obtain routinely 


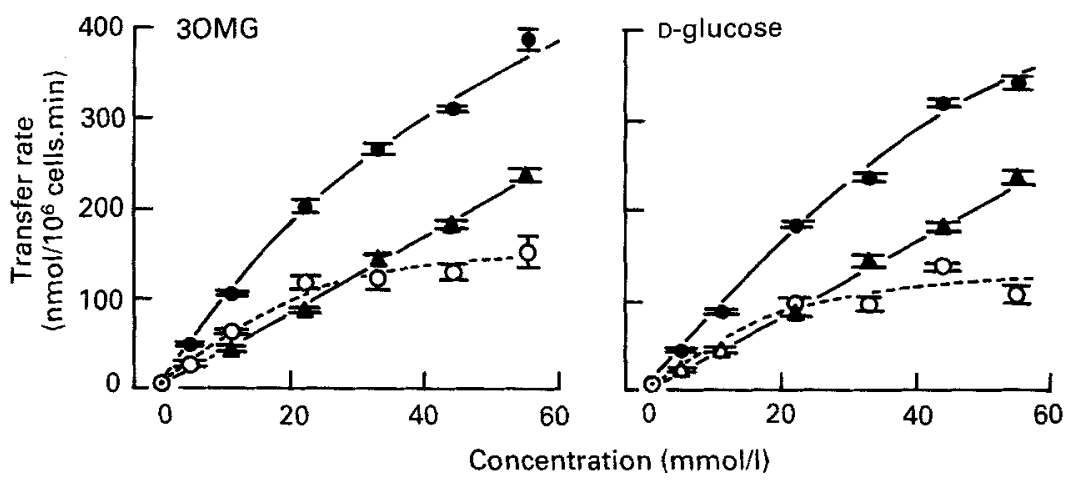

Fig. 1. Concentration dependence of transtrophoblast transfer of 3-O-methyl-D-glucose (3OMG) and D-glucose in the microvillous-to-basal direction. (-) , Total transfer of 3OMG and D-glucose; $(-\mathbf{\Delta}-)$, transfer of L-glucose; (- - - ) , difference between the total transfer of 3OMG or D-glucose, and that of L-glucose. Points are mean values with their standard errors, represented by vertical bars for preparations from four placentas.

an apparently continuous cover of confluent multinucleated cells over the surface of the amniotic membrane. The extent of the layer is illustrated in Plate 5 by the stained cross-section viewed at low magnification by light microscopy. So far as we can judge, the trophoblast layer consists of individual syncytial cells covering large areas; confluent, but overlapping in places. We also occasionally observe undifferentiated mononucleated cytotrophoblast-like cells under the syncytial sheet (Plate 3), as are observed in term placenta in vivo (Boyd \& Hamilton, 1975).

Transport characteristics. A start has been made into characterizing the permeability properties of this two-sided model at $2 \mathrm{~d}$ of culture. We have confirmed that molecular markers ranging from 2-aminoisobutyrate (relative molecular mass $\left(M_{r}\right) 103$ ) to human serum albumin $\left(\mathrm{M}_{\mathrm{r}} 68000\right)$ readily cross the amniotic membrane support by passive diffusion and that the cell layer forms a significant barrier after $2 \mathrm{~d}$ of culture. However, not surprisingly, the clearance of extracellular markers in the presence of the cell layer was still appreciable indicating a measurable leak (Bullen et al. 1990).

We have investigated the model further by examining the transtrophoblast transfer of D-glucose and its non-metabolizable analogue, 3-O-methyl-D-glucose, (3OMG) which are known to be transported across syncytiotrophoblast microvillous and basal cell membranes by carrier-mediated systems (e.g. Johnson \& Smith, 1980, 1985; Bissonette et al. 1981). Fig. 1 shows the concentration dependence of transtrophoblast transfer rates of $30 \mathrm{MG}$ and of L-glucose (the non-physiological isomer) in the microvillous to basal direction. The radiolabelled sugars were added at different concentrations to the medium on the microvillous side, and the initial linear rate of appearance in the basal compartment was measured. If the rate of transfer of L-glucose is taken as a measure of the diffusion-plus-leak component, then when this is subtracted at each concentration from the total $30 M G$ transfer rate, saturable $30 M G$ transfer is revealed. This indicated that transtrophoblast transfer of $30 \mathrm{OMG}$ involves at least one carrier-mediated step. The concentration which brought about the half-maximal rate of $30 \mathrm{MG}$ transfer was 55 $\mathrm{mmol} / \mathrm{l}$.

The results for D-glucose, again using L-glucose as diffusion-plus-leak marker, were 


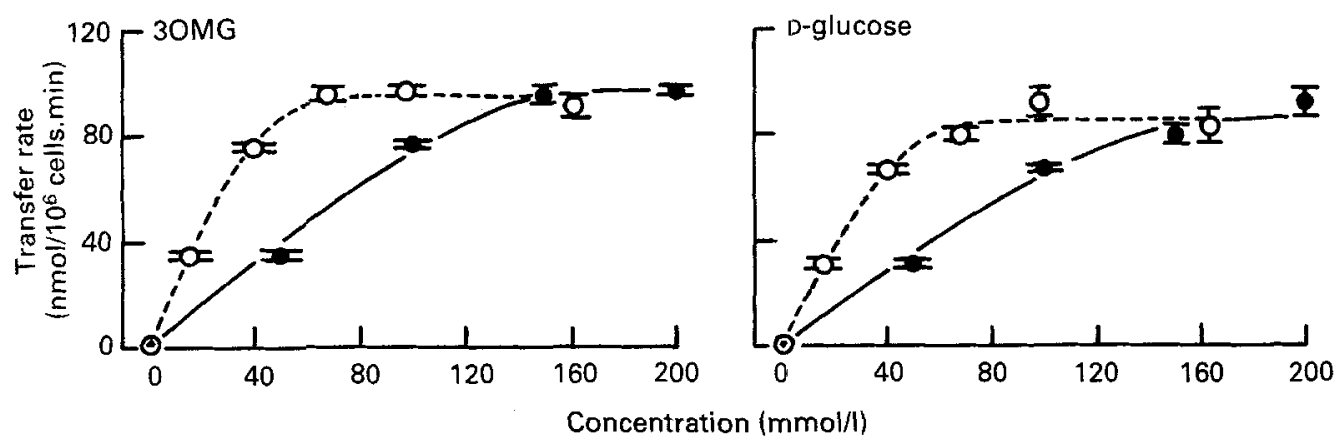

Fig. 2. Concentration dependence of transtrophoblast transfer of 3-O-methyl-D-glucose (3OMG) and D-glucose in the basal-to-microvillous direction. (-), Transfer rate of 3OMG or D-glucose $v$. the basal medium concentration $\left(C_{b}\right) ;(-\bigcirc-)$, transfer rates $v$. the calculated concentration at the basal membrane $\left(C_{m}\right)$. Transfer rates have been corrected for passive diffusion-plus-leak, as indicated in Fig. 1. Points are mean values with their standard errors, represented by vertical bars for preparations from four placentas.

very similar to those of $3 \mathrm{OMG}$, (Fig. 1) giving a concentration for half-maximal rate of transfer of $45 \mathrm{mmol} / \mathrm{l}$.

These results illustrate that although the diffusion-plus-leak component of the model is appreciable at the present state of development, it can be adequately controlled for if a suitable marker is available.

Another potential complication is the presence of the supporting amniotic membrane. Although it is relatively freely permeable, its presence will, in many situations, influence the transfer of solutes across the cell layer. This may for some studies be an advantage, in that it may represent a model of the in vivo situation where the microvillous membrane is in direct contact with the maternal blood, whereas there is a barrier on the basal side consisting of the basement membrane, stromal tissue and the fetal capillary endothelial cells.

However, for quantitative studies of trophoblast cell membrane transport per se, the possible effect of the supporting membrane should be considered. For example, in the basal to microvillous direction, for a given unidirectional flux $\left(J ; \mathrm{mol} / \mathrm{min}\right.$ per $\left.\mathrm{cm}^{2}\right)$ across the model there is a downward gradient of solute concentration across the supporting amniotic membrane, so that the concentration in contact with the basal cell membrane $\left(C_{m}, \mathrm{~mol} / \mathrm{cm}^{3}\right)$ is lower than that in the bulk medium $\left(C_{b}\right)$. The rate of solute transfer across the trophoblast cell layer clearly depends on the concentration at the basal cell membrane, not that in the bulk medium. $C_{m}$ can readily be calculated from the previously established identity describing the effect on solute concentration of a permeability barrier at the surface of a cell layer $C_{m}=C_{b}-\delta J / D$ (Winne, 1973; Dietschy, $1978)$, where $D\left(\mathrm{~cm}^{2} / \mathrm{min}\right)$ is its diffusion constant and $\delta(\mathrm{cm})$ its thickness. In addition to $J$ and $C_{b}$, the permeability of the supporting membrane $(D / \delta)$ must, therefore, be known or measured. Measurement is relatively straightforward in the present case.

We can apply this to the transfer of $30 \mathrm{OMG}$. Fig. 2 shows the concentration dependence of overall basal-to-microvillous transfer. These values have already been corrected for the passive diffusion-plus-leak components as described earlier. Rates of transfer $v$. the concentration in the basal medium, and the rates $v$. the calculated concentration at the trophoblast basal cell membrane are shown in Fig. 2. The latter more nearly 
represents the true transtrophoblast concentration dependence. It is clear that the presence of the amniotic membrane has a considerable effect on the apparent concentration dependence of 3OMG transfer. It can be seen from Fig. 2 that the same is also true for D-glucose transfer. If the effect of the supporting membrane were ignored, the apparent concentration for half-maximal rate of transtrophoblast transfer of $30 \mathrm{OG}$ and D-glucose across the cell layer, would be considerably overestimated. Measurement of the true $K_{m}$ of $3 \mathrm{OMG}$ or D-glucose transport at the basal cell membrane would be similarly overestimated.

Conclusion. These findings suggest that the two-sided trophoblast model is potentially suitable for investigation of transtrophoblast transfer, bearing in mind that the diffusionplus-leak component of transport, and the effects of the presence of the supporting amniotic membrane should both be taken into account where necessary.

The author gratefully acknowledges the support of the Wellcome Trust; Smith, Kline and French Laboratories and the Smith Kline (1982) Foundation.

\section{REFERENCES}

Aladjem, S. \& Lueck, J. (1981). Morphologic characteristics of the normal term human trophoblast maintained in prolonged in vitro cultures. British Journal of Obstetrics and Gynecology 88, 287-293.

Bãx, C. M. R., Ryder, T. A., Mobberley, M. A., Tyms, A. S., Taylor, D. L. \& Bloxam, D. L. (1989). Ultrastructural changes and immunocytochemical analysis of human placental trophoblast during shortterm culture. Placenta 10, 179-194.

Bissonnette, J. M., Black, J. A., Wickham, W. K. \& Acott, K. M. (1981). Glucose uptake into plasma membrane vesicles from the maternal surface of the human placenta. Journal of Membrane Biology 58, $75-80$.

Boyd, J. D. \& Hamilton, W. I. (1975). The Human Placenta. London: Macmillan.

Bullen, B. E., Bloxam, D. L., Ryder, T. A., Mobberley, M. A. \& Bax, C. M. R. (1990). Two-sided culture of human placental trophoblast. Morphology, immunocytochemistry and permeability properties. Placenta 11, 431-450.

Carter, J. E. (1964). Morphologic evidence of syncytial formation from cytotrophoblastic cells. Obstetrics and Gynecology 23, 647-656.

Contractor, S. F., Routledge, A. \& Sooranna, S. R. (1984). Identification and estimation of cell types in mixed primary cell cultures of early and term human placenta. Placenta 5, 41-54.

Contractor, S. F. \& Sooranna, S. R. (1988). Human placental cells in culture: a panning technique using a trophoblast-specific monoclonal antibody for cell separation. Journal of Developmental Physiology 10, 47-51.

Cotte, C., Easty, G. C., Neville, A. M. \& Monaghan, P. (1980). Preparation of highly purified cytotrophoblast from human placenta with subsequent modulation to form syncytiotrophoblast in monolayer cultures. In Vitro 16, 639-646.

Dietschy, J. M. (1978). Effects of diffusion barriers on solute uptake into biological systems. In Microenvironments and Metabolic Compartmentation, pp. 401-415 [P. A. Srere and R. W. Eastabrook, editors]. New York: Academic Press.

Fox, H. \& Kharkongor, F. N. (1970). Morphology and enzyme histochemistry of cells derived from placental villi in tissue culture. Journal of Pathology 101, 267-276.

Hoshina, M., Boothby, M. \& Boime, I. (1982). Cytological localization of chorionic gonadotrophin $\alpha$ and placental lactogen mRNAs during development of the human placenta. The Journal of Cell Biology 93, 190-198.

Johnson, L. W. \& Smith, C. H. (1980). Monosaccharide transport across the microvillous membrane of human placenta. American Journal of Physiology 238, C160-C168.

Johnson, L. W. \& Smith, C. H. (1985). Glucose transport across the basal plasma membrane of human placental syncytiotrophoblast. Biochimica et Biophysica Acta 815, 44-50. 
Kliman, H. J., Nestler, J. E.; Sermasi, E., Sanger, J. M. \& Strauss, J. F. (1986). Purification, characterisation and in vitro differentiation of cytotrophoblasts from human term placentae. Endocrinology 118, $1567-1582$.

Lobo, J. O., Bellino, F. L. \& Bankert, L. (1985). Estrogen synthetase activity in human term placental cells in monolayer culture. Endocrinology 116, 889-895.

Loke, Y. W. \& Burland, K. (1988). Human trophoblast cells cultured in modified medium and supported by extracellular matrix. Placenta 9, 173-182.

Loke, Y. W., Butterworth, B. H., Margetts, J. J. \& Burland, K. (1986). Identification of cytotrophoblast colonies in cultures of human placental cells using monoclonal antibodies. Placenta 7, 221-231.

Nelson, D. M., Meister, R. K., Ortman-Nabi, J., Sparks, S. \& Stevens, V. C. (1986). Differentation and secretory activities of cultured human placental trophoblast. Placenta 7, 1-16.

Stromberg, K., Azizkhan, J. C. \& Speeg, K. V. (1978). Isolation of functional human trophoblast cells and their partial characterisation in primary cell culture. In Vitro 14, 631-638.

Thiede, H. A. (1960). Studies of the human trophoblast in tissue culture. Cultural methods and histochemical staining. American Journal of Obstetrics and Gynecology 79, 636-647.

Truman, P. \& Ford, H. C. (1986). The effect of substrate and epidermal growth factor on human placental trophoblast cells in culture. In Vitro Cellular and Developmental Biology 22, 525-528.

Winne, D. (1973). Unstirred layer, source of biased Michaelis constant in membrane transport. Biochimica et Biophysica Acta 298, 27-31.

Zeitler, P., Markoff, E. \& Handwerger, S. (1983). Characterization of the synthesis and release of human placental lactogen and human chorionic gonadotropin by an enriched population of dispersed placental cells. Journal of Clinical Endocrinology and Metabolism 57, 812-818. 

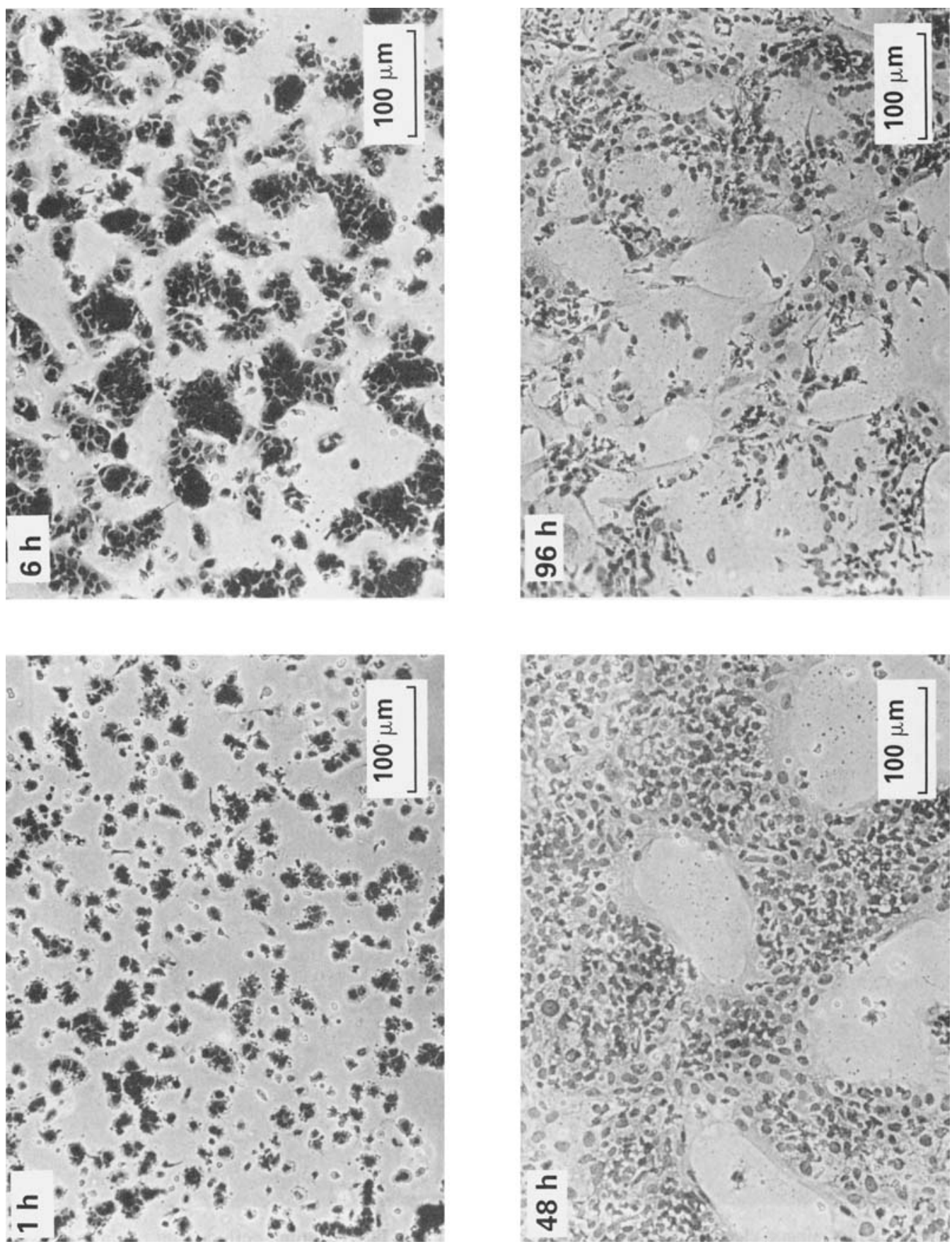

Plate 1. Light microscopy of the cultured cells at different time-periods after plating. Note the large areas of cytoplasm and clustering of nuclei at $96 \mathrm{~h}$.

DAVID L. BLOXAM 

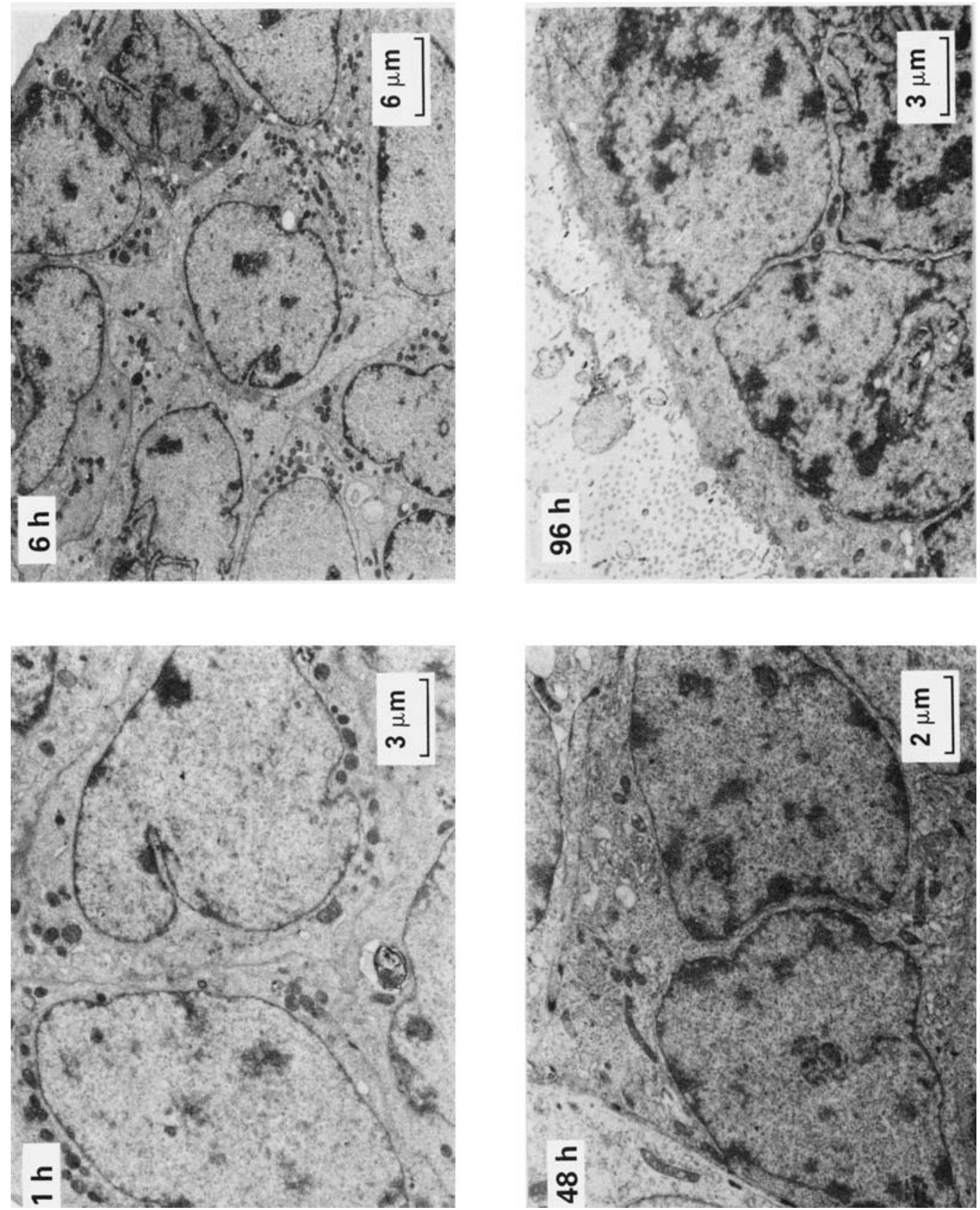

Plate 2. Transmission electron microscopy of the cultured cells at different time-periods after plating. At $1 \mathrm{~h}$, $6 \mathrm{~h}$, mononucleated cells showing simple ultrastructure. At $48 \mathrm{~h}$, multinucleated cell (right) adjacent to a mononucleated cell (left), with desmosomal junction (A). At $96 \mathrm{~h}$, part of a multinucleated cell showing characteristic clustering of nuclei and the presence of microvilli.

DAVID L. BLOXAM 

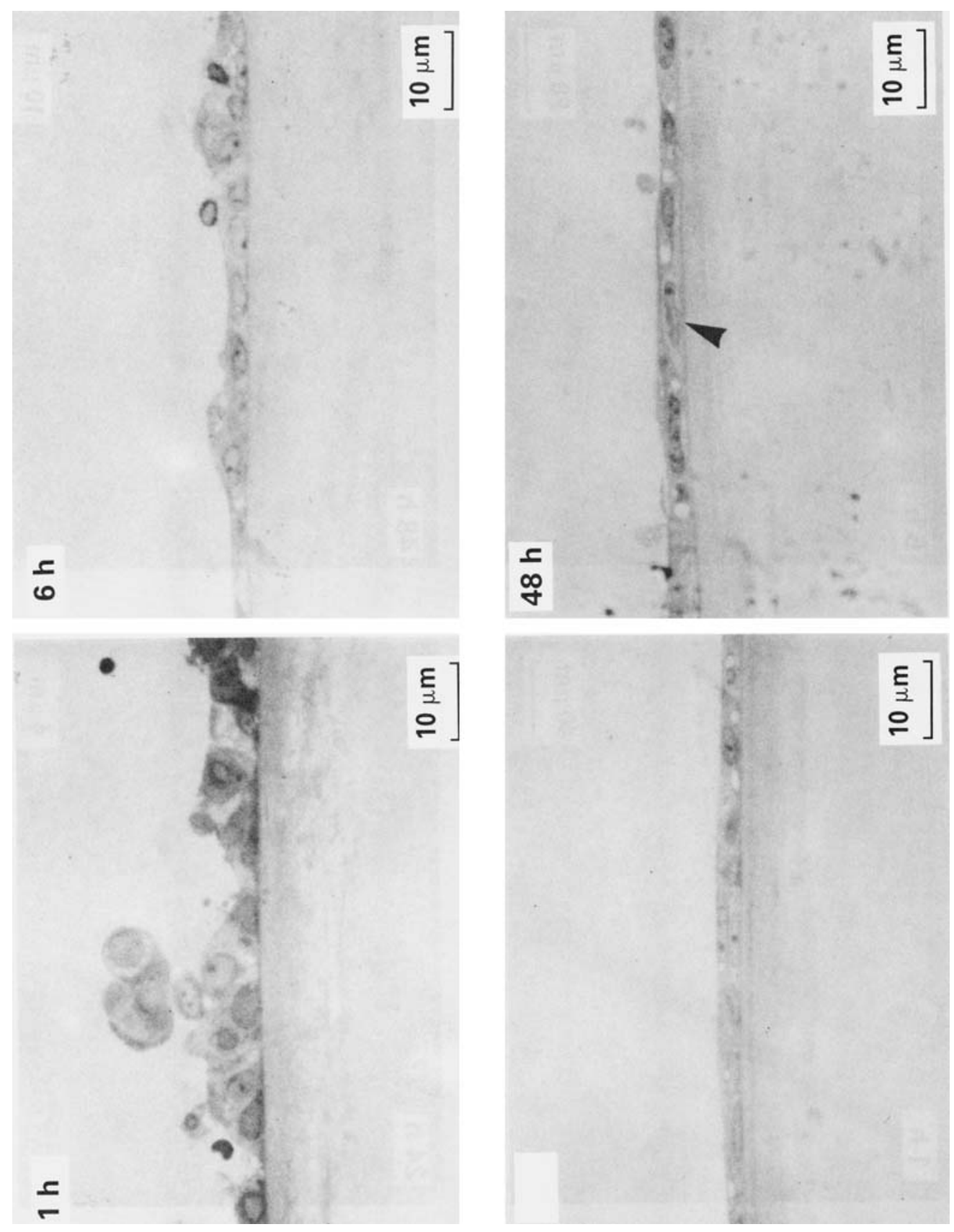

Plate 3. Stained semi-thin cross-sections of the trophoblast cells on amniotic membrane it different time-periods after plating. Note the presence of an isolated mononucleated cell under the multinucleated syncytium (A) at $48 \mathrm{~h}$.

DAVID L. BLOXAM 

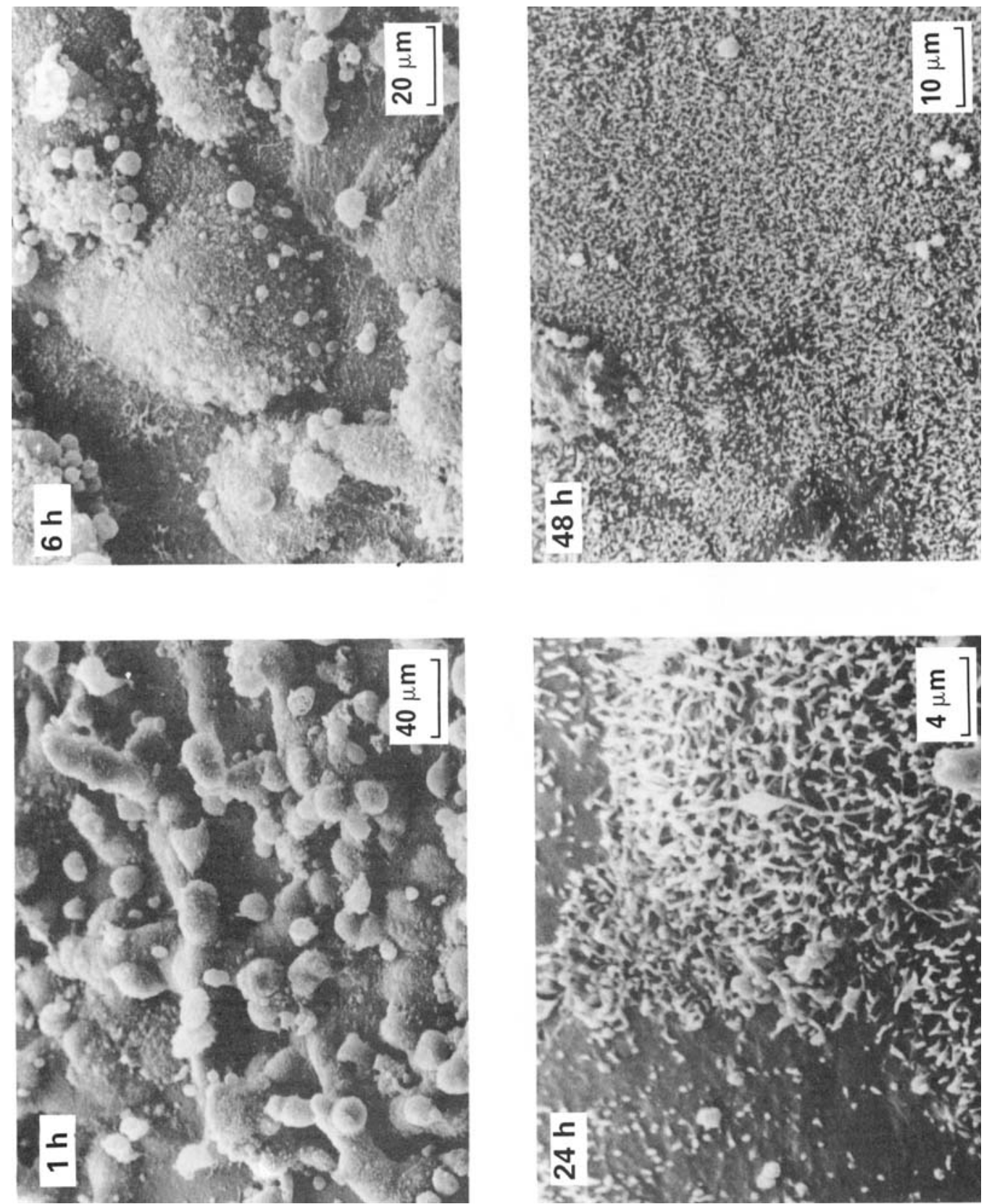

Plate 4. Scanning electron microscopy of the upper surface of the trophoblast culture on amniotic membrane at different time-periods after plating. At $1 \mathrm{~h}$, individual cells and clumps of cells. At $6 \mathrm{~h}$, cells flattening and starting to coalesce. At $24 \mathrm{~h}$, an apparently continuous layer has formed. Note variation of density of microvilli, presumably due to the presence of underlying cells at different stages of differentiation. At 48 h, note abundant, more uniformly distributed microvilli.

DAVID L. BLOXAM 


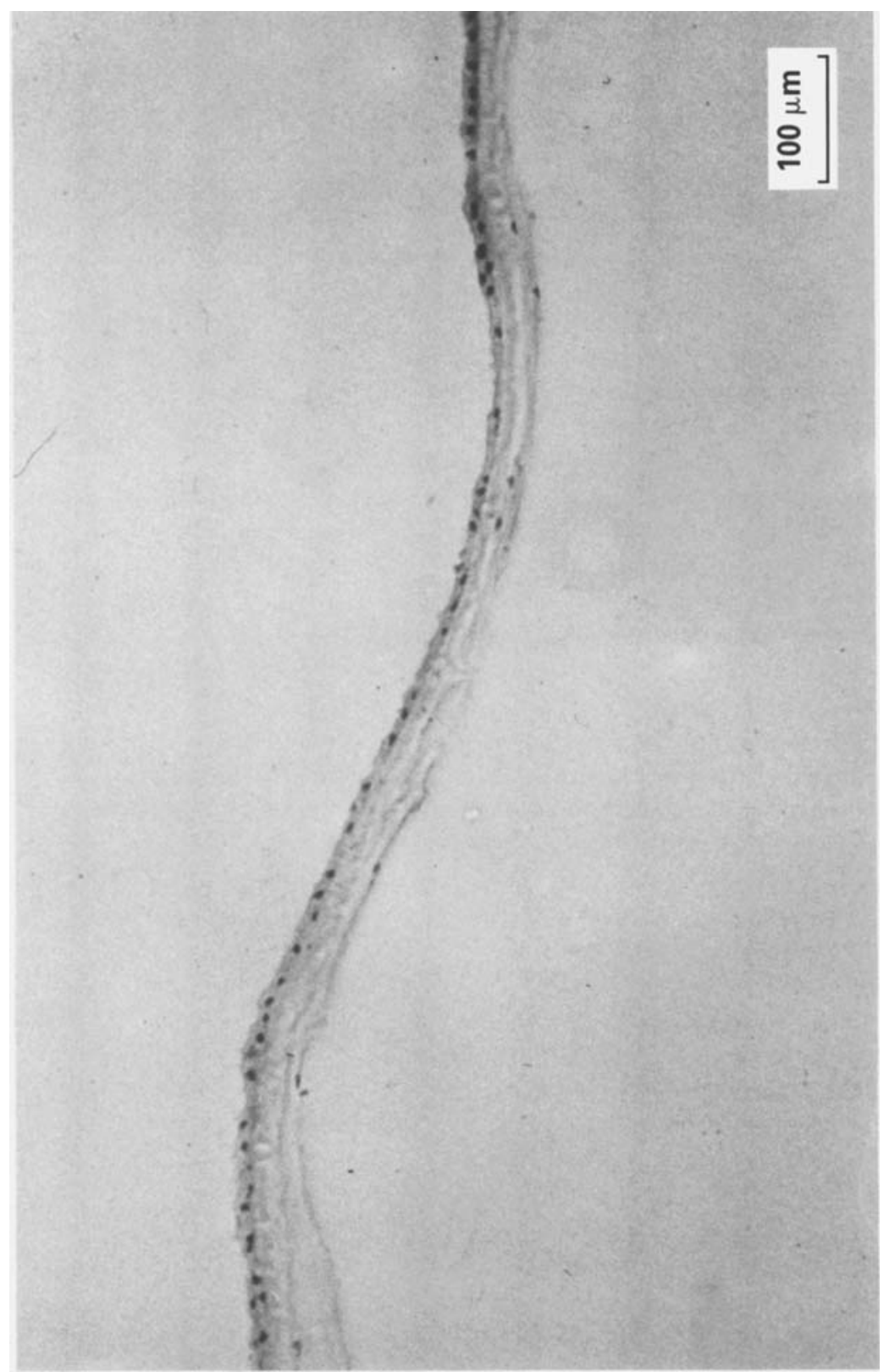

Plate 5. Light microscopy of a stained cross-section of trophoblast cultured for $48 \mathrm{~h}$ on amniotic membrane, seen under low magnification to illustrate the extent of the layer.

DAVID L. BLOXAM 